\title{
Online simulated workplace tasks to enhance business English learning
}

\author{
Thi Hong Le Vo \\ University of Economics Ho Chi Minh City, Ho Chi Minh City, Vietnam
}

\begin{abstract}
Purpose - This paper aims to provide evidence that online well-designed educational tasks can provide more relevant and richer active learning environment for business English learners. The benefits of online tasks, as an education tool, became more apparent and gained more importance during the events related to the Covid-19 pandemic. The task design is based on task-based interactions and in a sequence of tasks with the support of an online learning management system (LMS). The findings suggest that online task-based learning (and wouldbe blended learning in the future) enables meaningful and authentic activities promoting interactions and communicative competences to prepare for learners of business English to enter the workplace.

Design/methodology/approach - The overarching aim of the study is to explore how task-design-utilizing online LMS could contribute to enhancing the learning process and to the development of the learner's communicative competences. The study included two aspects, namely: (1) the design of online tasks and (2) pilot evaluation. The task design involved tasks that required interactions between the learners. The pilot evaluation relied on data collection via questionnaires.

Findings - Two aspects relating to the findings: (1) a description of the teaching initiatives which was designed to see how blended learning and online tasks can enhance learning and develop the skills of the learners: with questioning techniques targeting communication skills, simulated workplace situations and timely feedback and peer influence; (2) the findings of the pilot study evaluation to see the actual implementation of online tasks. The students' responses corroborate the teachers' comments. The findings of this research showed that LMS tasks, which were designed for this study, helped the learners to enhance their competence in business English. Such competences included communicative skills needed for learners to enter the workplace such as interpersonal skills, presentation skills and negotiation skills in contexts. These findings lead to significant recommendations regarding the way forward for developing active blended learning.

Research limitations/implications - Firstly, teachers need to be trained and involved in designing such online tasks and materials to be used in active blended learning. More training in language teaching methodologies should be investigated to adapt the transition from a traditional to a computer-assisted language learning teacher. This helps teachers to design and implement online simulated workplace tasks. Secondly, time for the use of online tasks should be allocated satisfactorily. This can be achieved by building online learning sessions into class schedule or developing active blended courses. The time for the use of online simulated tasks should be allocated satisfactorily with lab or simulation room, in which students would be shown how to access the online tasks designed on the university LMS and the way to practice with different kinds of tasks.

Originality/value - In this study context, the online tasks design can initiate at activity-level blending to support face-to-face (F2F) activities, for example, online activities to support tasks for the topic Make a request or Offer for help. This can be extended to course-level blending when more online activities are designed to use with F2F activities such as online comparing and contrasting tasks to develop skills in connections with the awareness of cultures. The findings of the research suggest to develop and to implement online tasks alongside with classroom learning and teaching to enable the objectives of business English programme at university for
\end{abstract}

JEL Classification - A20, A23, I20

(C) Thi Hong Le Vo. Published in Journal of Asian Business and Economic Studies. Published by Emerald Publishing Limited. This article is published under the Creative Commons Attribution (CCBY 4.0) licence. Anyone may reproduce, distribute, translate and create derivative works of this article (for both commercial and non-commercial purposes), subject to full attribution to the original publication and authors. The full terms of this licence may be seen at $\mathrm{http}: / /$ creativecommons.org/licences/by/4.0/legalcode.

The author is grateful to the teachers and learners of business English who enthusiastically participated in the study.

This research is funded by University of Economics Ho Chi Minh city, Vietnam.

simulated tasks for English learning

205

Received 1 June 2020 Revised 25 August 2020 25 February 2021 14 April 2021 Accepted 15 April 2021 
JABES 29,3 preparing learners to enter the workplace. The recent pandemic highlighted the need for effective methodologies for active blended learning. It is now required that professionals in higher education to collect evidence base to inform future practice of such methodologies. Further significant research efforts should be directed towards collecting such evidence of the effectiveness and improvements of such methods. The support of higher education management professionals in securing funding for such research will be essential.

Keywords Online task-based learning, Business English learners, Simulated workplace activities, Communicative competences

Paper type Research paper

\section{Introduction}

The need for communicative competence for business purposes has arisen when more jointventure companies have been in Vietnam for business. In these companies, employees typically interact in English with their colleagues, mainly through texting online or e-mail. Competencies needed include the use of written and oral communication such as greetings, making requests and answering requests, negotiating, working effectively in teams and writing an effective e-mail (Vo et al., 2016). However, it has been reported that graduates from the university had limited English proficiency, which challenges the graduates in using English communicatively as required at the workplace.

The Vietnamese authorities have recognized that English language education at university should be prioritized to meet the needs of both learners and employers (Vietnam National University-HCM, 2008), an understanding which has implications for materials design and teaching methods. Such a scenario seems more likely in a university context if the teachers themselves are able to design and use materials effectively, following principles that reflect a learner- and context-sensitive interpretation of communicative language teaching methods such as communicative language teaching (CLT) or task-based learning (Magubhai et al., 2004; Wyatt, 2011). These teaching methods focus on opportunities to communicate meaningful in a target language for learners to achieve communicative competences. In other words, tasks need to be designed according to pedagogical criteria and effective use.

The study contends that task design with the assistance of online learning management system (LMS) could help to deal with the challenges of creating work-related environments for learners to develop communicative skills. These tasks, alongside classroom teaching, support learners to practice presenting skills, negotiating skills, asking and answering requests and working in teams. This online learning environment provides flexible study options that enhance learning and increase students' self-directed study and engagement. The relevance of this study is further highlighted in the context of an increasing need for online teaching and learning worldwide due to the Covid-19 pandemic.

\section{Literature review}

This section outlines the major themes in the current literature that support aspects of the data analysis of this study. These themes include computer-mediated learning, authentic online tasks that business students need to prepare them for workplace communication as well as how blended learning using computer-mediated engagement supports learner's needs.

\subsection{Computer-mediated and blended learning to enhance English language learning}

Computer-mediated learning is not a new trend of English language learning and teaching. The findings of a number of previous studies, such as Levy and Stockwell (2006), Marques 
(2005), Nicole and More (2008), Kao and Windeatt (2014) and Vinther (2011), confirmed that elearning in learning English as a second language helped students to enhance their learning alongside classroom engagement.

Firstly, computer-mediated learning supports learners' communication with their fellow classmates and collaborative work. Social contacts can potentially be fostered by a number of ways in a computer-assisted language learning (CALL) environment including e-mail, electronic boards, discussion forums, discussion groups, e-mail lists, various chat programme, and web audio conferences. Group discussions are amongst the most popular; they make the student feel more involved in the course. Small group work projects allow developing a working collaboration, whereas large forum discussion allows for a community sense of learning. Discussion forums provide learners with time to formulate their questions (Marques, 2005; Nicole and More, 2008).

Secondly, computer-mediated learning creates an emotionally safe and supportive environment. The virtual social environment created by discussion forums or chat rooms can also have positive effects on introverted students' personality. A student who is socially shy can learn English by posting a message in a forum or in a chat room which can be much less "threatening." And students who never participate in class may be more inclined to do so in a virtual class environment and develop a confidence that could carry over to the real class environment. This emphasizes the importance of the teacher-moderator in these forums in securing an emotionally safe environment. This helps learners feel relaxed and stay engaged (Kao and Windeatt, 2014).

Thirdly, computer-mediated learning stimulates real communication. CALL will provide learners real-world situations. Insofar as they are involving real people having real discussions, one can certainly say the forum and chatting environments are real. It is conducted by language teachers and researchers that new mobile technology and multimedia (web cam) allow students to learn each other's native languages in real time and in a real situation. The students can work and follow their partner in their excursions or experiences, seeing all that his partner sees and dialoguing with him or her, as if they were together physically (Marques, 2005).

Recently, blended learning approach has become important in education settings. "Blended learning" is defined as a combination of different methods of learning or different learning contexts. Though it is not easy to arrive at one definition, blended learning is mostly defined as the strategic combination of online and face-to-face (F2F) learning experiences and instructions (Reay, 2001, pp. 1-6). In a pure online teaching classroom, students learn without direct interaction with teachers. A blended learning classroom is a mix of F2F and online teaching, which is an optimal approach in creating a dynamic, digital learning classroom. Singh and Reed (2001) defined blended learning as a learning programme with more than one delivery mode utilized in order to optimize the learning outcomes and cost effectiveness of programme delivery.

In higher education, blended learning is considered as a flexible approach to combine classroom instruction and technology. This approach allows the delivery of online training and assessment and in combination with other modes that can save costs and improve learning outcomes (Banados, 2006). In the context of language teaching and learning, the definition of blended learning is defined as a combination of F2F and CALL (Neumeier, 2005; Stracke, 2007).

According to Bojovic (2017), there are different levels that F2F and online foreign language instructions can be blended:

(1) activity-level blending, when both F2F and online learning are contained;

(2) course-level blending, where different online and F2F activities are used;

\section{Online simulated tasks for English learning}


JABES

29,3

(3) programme-level blending, where models and learners are offered F2F courses and online courses, or all blended courses; and

(4) institutional-level blending, where F2F classes at the beginning and at the end of the course, with online activities in between.

Singh and Reed (2001) identified benefits of blended learning approaches. Firstly, blended learning approach improved learning effectiveness by supporting students to gain knowledge and skills they want to acquire. In a physical classroom, the reach of a learning programme and knowledge transfer is limited to learners who can learn in a fixed time and location. With blended learning, when digital functions including the ability to playback a recorded live event are used for learning programmes, the reach can be extended to learners who cannot attend at a specific time.

Secondly, blended learning approach optimized programme development costs and time. Designing a web for training courses, for example, may be too expensive as it requires resources and multiple skills. Blended learning, a combination of e-learning events with text assignments, on the other hand, may be as effective or more effective.

Thirdly, learning outcomes or results are optimized with blended learning approach. Learning objectives can be obtained in much less class time than traditional teaching and learning methods.

The positive characteristics of computer-mediated and blended learning, as discussed above, have inspired teachers and curriculum developers in higher education worldwide to develop online materials to cater for an increased need of online learning or blended learning. This study looks at how online tasks can help to deliver authentic learning opportunities and encourage self-directed study off-campus alongside classroom teaching.

\subsection{Authentic tasks business students need to prepare for workplace communication}

2.2.1 The notion of genre of workplace communication. The notion of genre was identified as a systematic way of describing a variety of professional discourse (Schnurr, 2013, p. 53). Amongst the various definitions of genres, Bargiela-Chappini and Nickerson's (1999) definition is considered one of the most comprehensive: genres are "relatively stable forms of communication which develop in the course of production and reproduction of communicative practices and which are recognized by the members of that community" (p. 8).

Genres in the workplace were developed from eight communicative genres were grouped into three different macro genres by Koester (2006) in her corpus of American and British office talk (ABOT): unidirectional genres, collaborative genres and nontransactional genres. Unidirectional genres include procedural and directive discourse, briefing, service encounter reporting and requesting. Collaborative genres contain decision-making, arrangements, discussing and evaluating. These two genres are transactional which means "work-oriented", the interactions where the participants go straight to work. Non-transactional genres including the two specific genres of small talk and office gossip, on the other hand, concern topics outside work and "off-task" talk about work (Koester, 2010, p. 25). Two procedural subgenres defined in ABOT corpus are general instructions or explanations of procedures and directives or instructions relating to a specific instance. Directives are identified to have an important role within encounters involving instructions and procedures and also occur within other genres such as decisionmaking (Koester 2006, 2010).

It is evident in researches (Koester, 2010; Schnurr, 2013) that new employees entering the workplace need communicative competence in English, e.g. to help them make requests, issue and follow directives, and write business e-mails. In the same vein, previous researches 
(Vo et al., 2016; Vo, 2017) show that communication strategies such as opening and ending a conversation, making requests and negotiation are required for employees at the workplace. Managers of the companies stated that communication strategies are more important than linguistics skills in workplace communication. In other words, the companies emphasized intercommunicative competence such as teamwork skills, interpersonal skills and negotiation skills to make a successful conversation in business for both spoken and written English. Lack of such skills could cause obstacles in career progression of graduates even when they were competent in their specific technical field.

2.2.2 The importance of task-based learning for business English learners. As discussed above, there is a huge need to be able to effectively communicate in English for business purposes. Ho Chi Minh City, where the study was carried out, is not an exception. The need requires graduates not only communicative strategies such as how to make requests, directives or write business e-mail but also cultural behaviours for international communication. It raises the importance of English learning tailored to the workplace needs of graduates (Vietnam National University-HCM, 2008). It resulted in the objectives of the programme at the university which indicates the required topics include opening and ending a conversation, giving directions and describing responsibilities at the workplace; making requests and offers of help at work; negotiation skills (Vo et al., 2016).

In details, the learners need learning opportunities to be able to communicate in real-life situations, which are as follows:

(1) English being prepared for students to be able to study the content subjects in English and to participate in exchange programmes that provide the learners opportunities to access international business courses.

(2) English being prepared for graduates as a language in lingua franca used in workplace and business interactions. The other important thing to prepare for graduates is that the understanding of the influence of local cultural factors and the different cultural behaviours from foreign colleagues who are non-native English speakers (Japanese, India, Chinese, Korean) rather than native English speakers (Vo et al., 2016).

In order to meet the need, it requires approaches in English language teaching which concern authentic materials such as emphasizing communication through meaningful interaction amongst learners (Richard and Rogers, 2011). If the argument that learners need to see evidence of how the English they learn can operate in the real world (Dat, 2008) is accepted, this suggests that the use of authentic materials might be advantageous. Indeed, opportunities for learners to use English meaningfully to fulfil communicative purpose could be provided with such materials (Clarke, 1989; Trabelsi, 2010). It is task-based language teaching $(T B L T)$ that would support to fulfil the requirements discussed above.

$T B L T$ is considered as a coherent approach that focuses on supporting learners to communicate meaningful in a target language. This approach brings the advantages for CLT, includes: "Activities for real-life communication, activities in which language is used for meaningful tasks, meaningful language to support the learning process” (Nunan, 1991, p. 303). Such tasks with the support of online LMS to enable meaningful and authentic activities for learners will be presented in this paper.

\subsection{Blended learning and online task design to support learners' need}

Research has reported the positive effect of interactions with computer support. Skehan (2003), for instance, evaluates interaction tasks important as "interactive tasks produce markedly more accuracy and complexity" (p. 349). Vinther (2011) supports the results reported by Levy and Stockwell (2006) that learners involved in interactions "demonstrated 
JABES 29,3

\section{0}

increases in both the accuracy and the complexity of the language produces" (Levy and Stockwell, 2006, p. 104).

Firstly, the online tasks design will support teachers and learners to go further for the contents learnt from the textbook. The methods such as F2F discussion, facial expressions and other non-verbal cues can be supported by online tasks for business English learning. Whilst these tasks support teachers with authentic pedagogy, they assist students to engage in the learning process in order to master what they have learnt in class (Skehan, 2003; Vo, 2017). In other words, digital tools can serve authentic ends. For example, a teacher may ask his students to watch a video of high-context and low-context cultures. Students then work in person and discuss with friends to answers questions or fill in a table of information about doing business in different cultures. This is an authentic activity, and it has all students engage in.

The other important reason to have online tasks is that this helps distance learning. Learning English on computers increases the time students learn English, and they can learn in flexible time. Despite of outside class, these computer-assisted tasks provide students an interest in learning English. It provides students more opportunities to know how the language is used in simulated real situations, which bring the meaning of learning a language (Warschauer and Healey, 1998).

Finally, the coronavirus pandemic has impacted every aspect of our lives including higher education. Universities were required to suspend $\mathrm{F} 2 \mathrm{~F}$ classrooms replacing them with virtual classrooms to ensure the safety of teachers and students. In the light of the current demand for online learning, this research aimed at investigating how online tasks can support effective learning and engagement of the students who were studying business English. The focus was on achieving communicative competences required for the work place. This paper discusses how authentic learning of business English can be achieved by well-designed online tasks when combined with classroom learning activities.

\section{Methodology}

The overarching aim of the study is to explore how task-design-utilizing online LMS could contribute to enhancing the learning process and to the development of the learner's communicative competences. The study included two aspects, namely: (1) the design of online tasks and (2) pilot evaluation. The task design involved tasks that required interactions between the learners. The pilot evaluation relied on data collection via questionnaires.

\subsection{Design of online tasks}

The design of such tasks and procedures included two stages: Firstly, it was emphasized that graduates need to be prepared to meet English requirements that new employees entering the workplace need communicative competence in English, e.g. to help them make requests, issue and follow directives, and write business e-mails (Koester, 2010; Vo et al., 2016). The tasks, therefore, are designed to tailor to the requirements of English at the workplace for graduates, as follows:

(1) describing responsibility;

(2) opening and ending a conversation;

(3) issuing and following directives; and

(4) making requests and negotiation.

Traditionally, the common types of task include listing, ordering and sorting, comparing, sharing personal experiences, problem-solving and creative tasks (Willis, 1996). In terms of 
the type of interaction that occurs in task accomplishment, tasks are categorized as information gap tasks, jigsaw tasks, decision-making tasks, problem-solving tasks and opinion exchange tasks (Richards and Rogers, 2011). In this study, the above types of interaction tasks are applied to the task design for the objectives of the study.

Moreover, tasks need to be designed in a sequence of tasks to develop communicative competence for learners. As it is suggested by Tomlinson's (2003) text-driven framework, the designed materials would be fully explored to go further than one or two tasks for supporting learner's communicative competence. The tasks in this study are designed in a sequence of tasks to develop skills such as giving directions, making requests and negotiation skills for learners. In the next stage, the online LMS enables task design by providing different tools as it is discussed below.

Secondly, the online tasks were designed with LMS. LMS is an online learning management system used at the university. As mentioned in part 2 above, computermediated learning has enhanced English language learning; this system supports teachers to design different tasks for blended teaching and learning, which includes:

(1) Quiz: multiple-choice, short-answer that enables teachers to create exercises.

(2) The page is offered to teachers to use for lessons or web page resources because it can display text, web links, sound and video.

(3) Assignments are used the most because of its advantages: the assignment module supports tasks design with word-processed documents, images, audio and video clips. With this activity module, an assignment can be designed in the way that it reminds students of "real-world" assignments they need to complete off-line, thus not require any digital content.

(4) The feedback activity module is the other important module because it supports the assessment. This is an important function that helps teachers to have feedback on the tasks from learners to pre-evaluate the tasks and to improve the content for later participants. Feedback forms can be designed with a variety of question types including multiple choice, yes/no or text input in this activity module.

As for the purpose of the tasks designed in the study, kinds of tests such as "short answers", "assignments" and "page" in the system are chosen. These forms are a good choice to display the lessons, run exercises with audio and video clips. It also allows learners to upload their own audio clip designed for the requirements of the tasks (Figure 1). These functions bring benefits for developing interaction skills fitting the major objectives of the tasks design in the study, as it is discussed in the next part of the study.

\subsection{A pilot evaluation}

A pilot experiment was carried out for a preliminary evaluation of the implementation of the designed online tasks.

3.2.1 Participants. Learners and teachers of two classes, Business English course, at a university were chosen for this study. The study involved 31-32 students from each class. The students' English language proficiency was at pre-intermediate levels of English. The two classes involved in this study were related to Business English Part 2 (BE2). It is noteworthy that these classes had studied a prerequisite course of Business English Part 1 (BE1) at the same university. The learning outcomes of these courses focus on achieving important English communication skills such as interaction skills and negotiation skills.

At the onset of the research project, full briefing to the learners was carried out to explain the objectives of the research and to explain how the tasks could support the development of
Online for English learning 


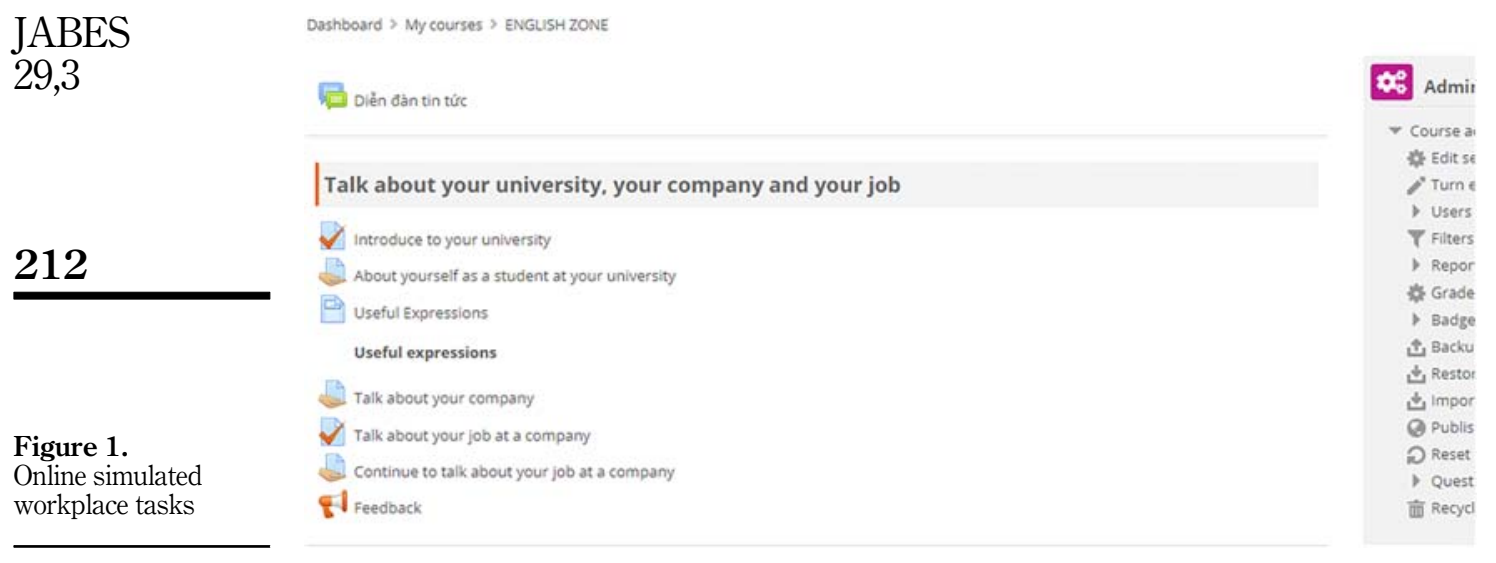

their communication skills to fulfil the requirements of the learning outcomes of their course. In addition, clear instructions were given to make sure the students understood the procedure to fulfil the requirements of the tasks. Following the detailed briefing, the participating students were asked to read the documents related to research ethics and consent forms. Using these methods, 47 of the 62 students in the two classes agreed to participate.

The data reported here relate only to the students who formally consented to participate in the research project. For the homework and assignment requirements, during the 9 -week duration of the course, the learners were asked to carry out the online tasks instead of off-line tasks which was the method used for the prerequisite course, BE1.

The teachers, who consented to participate in the study, held Master of Arts in Teaching English to Speakers of Other Languages qualification. The teachers had 7- to 9-year experience of teaching business English. They were all interested in such aspects of computer-aided learning; hence, they were supportive of the research efforts.

3.2.2 Instruments. Two survey questionnaires were designed for the purpose of gathering data on the pilot evaluation of the implication of the online tasks; one for the students and one for the teachers.

3.2.2.1 The survey questionnaire for students. This was designed as an online feedback form to explore the significance of potential of students' behaviour doing the online tasks in the study. The questionnaire contains six main questions. The first five questions concerned the students' perception and self- assessment of their practice with the online tasks. These questions were used to find out how much the online task can support learners to enhance what they learnt in class and develop communication skills. Learners were asked to give the answers on Likert's scale that best describes their choice from 1 (very little) to 5 (a lot). Some open-ended sub-questions to explore reasons for their answers and further comments were also used. These questions were as follows:

(1) Q1: How much do you like the tasks?

(2) Q2: How much the tasks support you to enhance what you have learnt in class?

(3) Q3: Which communication skills do you think these tasks support you to achieve? For example, listening skill, speaking skill, writing skill, problem-solving skill and interpersonal interaction.

(4) Q4: Some more communication skills (that these tasks support you) you would like to add? 
(5) Q5: How much do you think that these tasks prepare you with cultural values for international trade and business communication?

(6) Q6: "Doing these online tasks or off-line tasks, which one do you prefer? Why?"

The last question (Q6) was open-ended to obtain the students' comments regarding how the online tasks compare with the traditional off-line tasks.

3.2.2.2 Survey questionnaire to teachers. This was designed to gain the information to verify the results of the students' responses as well as to evaluate the student - teacher differences in perceptions. The two main questions to teachers were as follows:

(1) How do you evaluate learner's doing the online tasks comparing to doing off-line tasks for further practice?

(2) Would you suggest using these online tasks to enhance business English learning? Why? Your suggestions for the implementation of these online tasks.

3.2.3 Data collection. English sessions BE2 recruited for the study were scheduled within 9 weeks. The online tasks for the study were carried out over that period of time. Student participants did the tasks as assignments given and instructed by the teachers for further practice to enhance what the students learnt in class during the course.

The questionnaires for the students and teachers were delivered at the end of the course. The teachers, who had been informed about the study, explained to their students the purpose of the study for the students to complete the survey online at the final week of the course after learners doing all online tasks. The questionnaire for the teachers was given with clear and adequate explanation for its purpose. The teachers answered the questions by e-mailing it to the researcher. In approaching the data, "sequential analysis" of discourse (Silverman, 2005) was adopted, in which the two data resources (survey to teachers and students) were analysed and integrated, split into segments and then made into themes.

The delivery of this 9-week teaching course started in January 2020 before the Covid-19 measures were introduced at the university after 6 weeks from the start of the teaching weeks. Therefore, 6 weeks were delivered as F2F teaching and 3 weeks were delivered online. However, the online tasks were introduced and adopted right from the start of the teaching weeks in January 2020. When the F2F teaching was suspended for the last 3 weeks of the course due to the Covid-19, the online tasks gained even more importance to achieve the learning outcomes.

\subsection{The consideration of ethical issues}

Whilst conducting the study, the author considered the importance of the accuracy in collecting reliable data and reporting the research findings as outlined by Holliday (2002). The reliability of the data relates to those patterns that existed throughout the data rather than being influenced by the researcher's personal perspectives or power imbalance. It is thus a key that the researcher was not teaching and had not known the student participants. The students participated voluntarily to do the tasks and give feedback. This is to avoid threatening that may cause the participants to be reluctant to express and clarify their ideas, which could influence the validity of the data.

\section{Results and discussion}

This section will present two aspects related to the findings: (1) a description of the teaching initiatives which was designed to see how online tasks can enhance learning and develop the skills of the learners and (2) the findings of the pilot study evaluation to see the actual implementation of online tasks. 
JABES 29,3

\section{4}

Figure 2.

An online task to develop communication skills

Figure 3.

Online tasks for making requests and negotiation skills at work
4.1 Blended learning with online tasks to enhance learning and develop the skills of learners 4.1.1 Interactive activities with questioning techniques targeting communication skills. Teachers can embed interactive activities directly into their class lectures (Singh and Reed, 2001) that reduce students' "seat time" by moving from passive to active lectures. In comparison with off-line tasks, online tasks create more opportunity to use questioning techniques to develop interaction skills (Marques, 2005; Warchueer and Healey, 1998). Whilst activities for off-line tasks could be limited in "learners reading the given texts and answering questions," activities in online tasks allow learners to watch the videos or listen to the audios and answer the questions. Furthermore, more open-ended questions can be used to provoke students' brainstorming and to think about the topics, e.g. introducing their university or their companies, the cultural differences in negotiation (e.g. see Figure 2).

For example, in one task, students are asked to watch the video and answer the questions.

Through the process of doing this task, students are prepared for the tasks of talking about their companies and their jobs by answering questions such as:

Where did your company headquarter?

When was your company founded?

How many employees in your company?

What is your position in the company?

The other online tasks such as offering for help and asking a request; low-context and high-context cultures in doing business; how to conduct negotiations can also be done through questioning techniques (Figure 3). For example, after students watching the videos attached in the tasks, learners will answer the following questions:

What is important when negotiating with someone from another culture?

Which countries and regions below do you think are low-context or high-context cultures?

The video clips or audio clips included in the online tasks present authentic materials that help learners' mental readiness by arousing their attention (Sherman, 2003; Kao and Windeatt, 2014). Once they have mental readiness, learners are engaged in answering the questions and performing the task. When answering the questions, learners are encouraged to think deeply about the tasks. This can help to develop communicative skills needed for learners to enter the workplace such as presentation skills and interpersonal skills. In other words, online tasks support the use of questioning techniques for the development of

Please watch the video via the link and answer the following questions:

https://drive.google.com/file/d/1yRKoqZWypqJYjexUWV2ReV8WUPZb4pd/view?usp=sharing
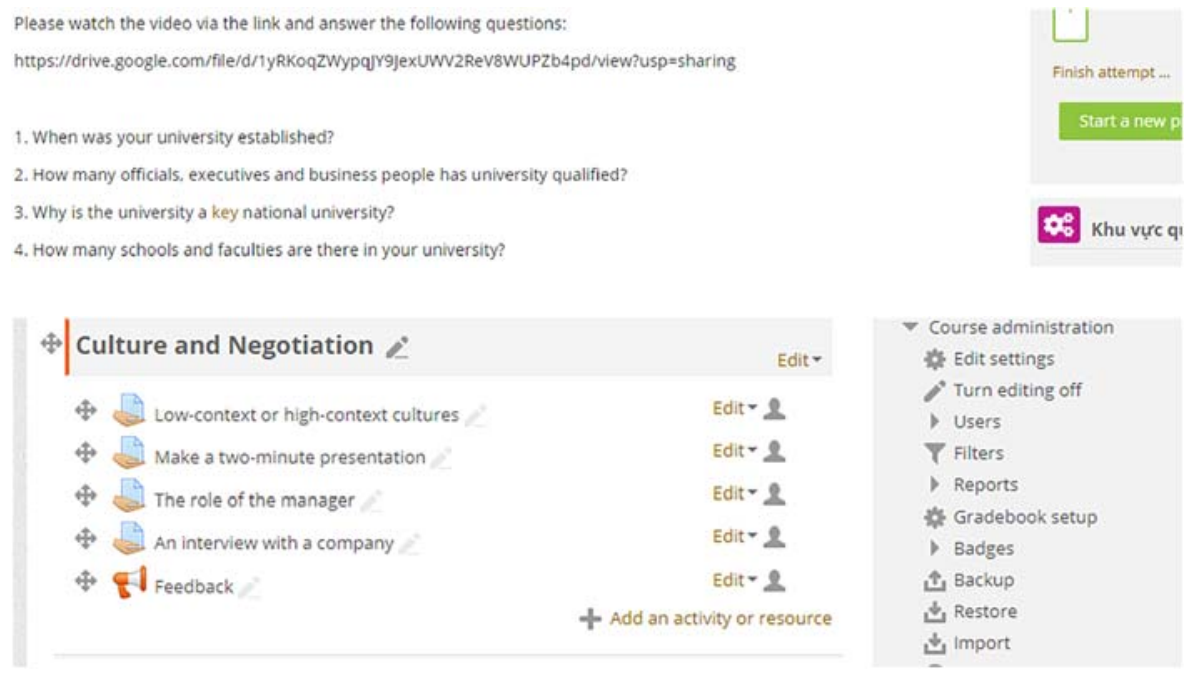
conversational skills such as turn taking; self-determination (Van Lier, 1996) and decisionmaking, arranging, and discussing skills (Koester, 2006, 2010).

4.1.2 Audio clips for simulated workplace situations. Audio clips can support blended F2F and online language instruction $t$ by providing more motivation compared with off-line tasks as it facilitates the production of audio and clips for simulated workplace situations. In a number of online tasks in this study, learners are asked to have their answers by making their own audio records.

In other tasks for the topic “Make a request" or "Offer for help”, learners are asked to make a conversation in real-life or simulated workplace situations with their partners. The tasks might be: "Your phone isn't working and you are asking one of your colleagues for help" or a telephone conversation between a customer and a member of staff. Once online, the learners can create an audio clip of their conversations easily to post it on LMS with a voice recording application installed on their computers. The activity of making their own audio clips provides more opportunities for learners to practice in the way that it could generate learners' communication based on meaningful situations to make learners to speak English.

Then, tasks can be developed in a sequence of tasks (Tomlinson, 2003) that after learning the reasons for the failure of the conversation between a manager and a subordinate, learners are asked work in pairs or small groups to play roles of the manager and the employee(s) for a successful negotiation. The learners will then exchange their work with the others to compare and have comments. There are model answers for learners to check if necessary. This process can help learners to learn from each other and review useful expressions used for making requests and offering (Schnurr, 2013; Koester, 2006). This enhances what learners have learnt in class. By making their own audio or video clips or with their partners, learners are provided opportunities to create the tasks themselves (Willis, 1996; Richards and Rogers, 2011), develop self-study skills and teamwork skills. Furthermore, this supports meaningful language production based on what they have already understood from the text.

\subsection{Timely feedback and peer influence in combining online e-learning with text assignments}

A combination of e-learning events with text assignments is more effective than pure off-line traditional teaching and learning. Online tasks allow comparing and contrasting activities, which could be time-consuming if they are done as off-line tasks. For example, it could take $15 \mathrm{~min}$, in online environment, for learners to listen to a model audio clip, a video clip or an online clip from their classmates. The students can then make comparison with the audio clip they produced. Whereas, in off-line environment, it could take double as much to perform such tasks in the classroom due to the big class size. The benefit of this activity is to provoke students' brainstorming and thinking deeply about the content they are studying

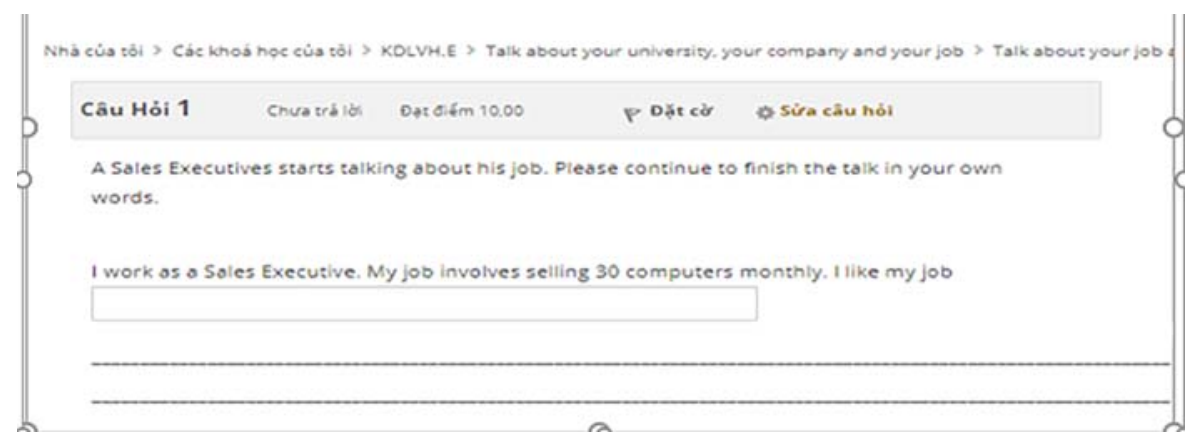

Online simulated tasks for English learning

215
Figure 4.

An online task encouraging learners to have their own audio clips for their answers 
JABES 29,3

\section{6}

(Tomlinson, 2003). In addition, the online tasks provide a timely mechanism for providing feedback to the students to identify their strength and weakness in the use of language. The added benefit of group interactions online leads to social learning activities where peer learning takes place.

As an example shown in Figure 5, the learners can compare their own clips or their classmates' clips with the model answers by listening to the model answers as a mechanism of providing immediate feedback just after finishing their recordings.

In the other tasks, learners learn how to conduct a negotiation successfully by listening and comparing the two model audio clips provided on an LMS assignment module - How to conduct negotiations. As researchers (Levy and Stockwell, 2006; Vinther, 2011) said, the interactions amongst learners increase the accuracy of the language produces. This online activity speeds the process of learners' grasp of "The rules for negotiations" and knowledge of useful expressions such as "Well, I d like to help you, but. ..", "I am afraid I cannot..", "Could you...?", "That's acceptable, as long as...". These tasks activate learners' existing knowledge of the target knowledge and cultures as well as awareness of the influence of their native culture when doing the task.

Online comparing and contrasting tasks also help to develop skills in connections with the awareness of cultures. For example, learners are asked to watch the two video clips of lowcontext and high-context cultures comparison and answer the questions (Figure 6). For this task, students work in groups to find the answers. This task gives the need of communicating with their classmates indicates that it could simulate tasks that support learners to work in groups to discuss and answer the questions (Nicole and More, 2008; Warschauer and Healey, 1998).

From this, learners will think about how different it is in negotiation with different cultures. This prepares learners negotiation skills to work with colleagues who come from different cultures. The benefit of this online task is that learners are encouraged to study more about doing business in a multi-cultural environment. It also allows learners a flexibility in

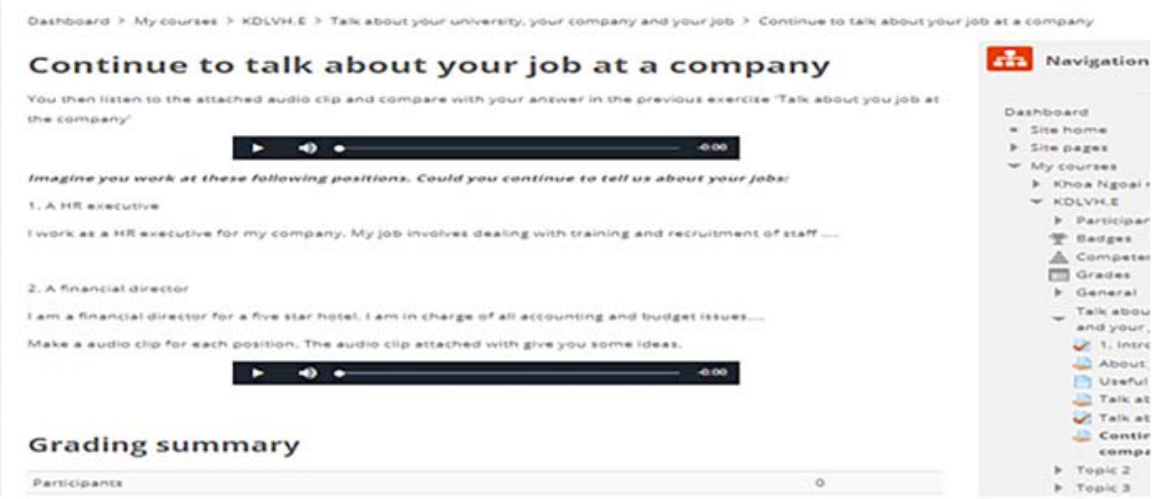

Figure 5.

An online task to support learners to compare their own clips with the model answers

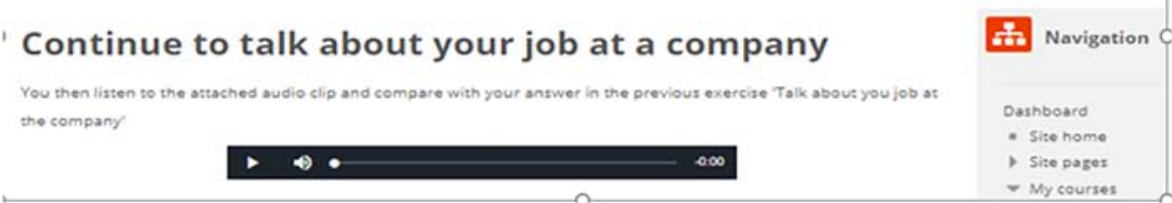


time and different learning styles that could be appropriate for a big or small group of learners.

\subsection{Findings of the pilot evaluation}

The data analysis presented here identifies students' attitude and feedback on doing the online tasks compared to off-line tasks and outlines the teachers' ideas of the implementation of the online tasks.

4.3.1 Student's feedback. Table 1 outlines the learners' responses to the questionnaire after doing the online tasks.

The output of the responses in Table 1 indicated that most of the students found the online tasks useful and supported them to enhance what they learnt in class. The percentage of students who chose " 5 " or "4" (a great deal) for "the online tasks support you to achieve communication skills" was 51 and $44.5 \%$, respectively. The communication skills, in question, included listening skills, speaking skills, writing skills, problem-solving skills and interpersonal interaction. The responses of "The online tasks prepare you with cultural values for business communication" showed that the majority of the students, total of $91.8 \%$, responded with either 5 or 4 (a great deal).

As for the last question related to cultural issues, $75 \%$ of the students responded that they preferred learning with online tasks. The reasons for their answers, which are not edited and direct quotations, were as follows:

(1) I prefer LMS to traditional media because I love flexibilities. It makes me feel more comfortable.

(2) I prefer task on LMS because it is very convenient and also easy to complete. I do hope there is a lot of tasks like this in the future.

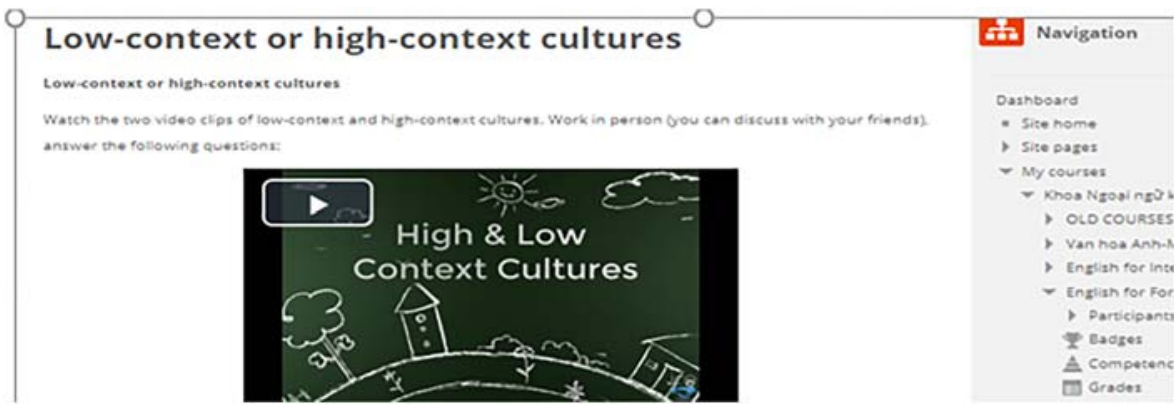

\begin{tabular}{lllcccr}
\hline How much do you think the online & \multicolumn{2}{c}{ A great deal } & Average & \multicolumn{2}{c}{ A little } & \\
tasks...? & \multicolumn{1}{c}{5} & 4 & 3 & 2 & 1 & Total \\
\hline $\begin{array}{l}\text { You like the online tasks } \\
\text { Support to enhance what you have }\end{array}$ & $21(27 \%)$ & $29(62 \%)$ & $5(11 \%)$ & $0(0 \%)$ & $0(0 \%)$ & $47(100 \%)$ \\
learnt in class & $24(51 \%)$ & $21(44.5 \%)$ & $2(4.5 \%)$ & $0(0 \%)$ & $0(0 \%)$ & $47(100 \%)$ \\
$\begin{array}{l}\text { Support you to achieve } \\
\text { communication skills }\end{array}$ & $23(49 \%)$ & $3(6.4 \%)$ & $0(0 \%)$ & $0(0 \%)$ & $47(100 \%)$ \\
Prepare you with cultural values & $22(46.8 \%)$ & $21(45 \%)$ & $4(8.2 \%)$ & $0(0 \%)$ & $0(0 \%)$ & $47(100 \%)$
\end{tabular}

for business communication

\section{Online simulated tasks for English learning}


JABES

29,3

\section{8}

(3) LMS is better. Because I can talk until I satisfy with my assignment.

(4) Doing on LMS help me have more time to look for the information and through that I can learn a lots things outside class. It's very helpful.

(5) I prefer doing the assignment on LMS. Because I can have more time to review and prepare the task more carefully. In this way, I can be more confident with my result.

(6) Do tasks on LMS, we could save time and may deal with some unwanted trouble like Covid-19.

4.3.2 Teachers' responses. Similar to the responses from the students, the two participant teachers showed positive attitudes towards the online tasks.

In their statements regarding how online tasks compared with the off-line task methods, the participating teachers observed two key aspects. One aspect was related to how punctual the students submitted their coursework. The other aspect was related to how motivated and engaged the students were. This was evident by the fact that the students were excited to seek feedback from the teachers and keen to start new topics. Most of the students also had good scores for the tasks, which indicated that these tasks help learners to enhance what they learnt in class and develop language skills.

In addition to the positive findings above, as mentioned before in Section 3, the Covid pandemic occurred at the middle of BE2 course (scheduled from January to March) magnified the urgent need of online learning. Therefore, though the teachers admitted that they had obstacles regarding time and investment to design online tasks, they suggested these online tasks should be used more for homework assignments or active blended learning courses.

In summary, the students' responses corroborate the teachers' comments. The findings of this research showed that LMS tasks, which were designed for this study, helped the learners to enhance their competence in business English. Such competences included communicative skills needed for learners to enter the workplace such as interpersonal skills, presentation skills and negotiation skills in contexts. These findings lead to significant recommendations regarding the way forward for developing active blended learning.

Besides the positive feedback from all participants, some difficulties were mentioned by the teachers mainly regarding time constraint, workloads and technological abilities. Very small minority of the students, less than $10 \%$, indicated that they preferred the immediate physical contact with the teachers during performing the tasks. The views of such minority should also be taken into consideration during the implementation of the tasks.

\section{Recommendation}

The findings of this research suggest that online tasks can provide more effective practices for language learning and teaching. This indicates that online tasks should be developed to support traditional classroom learning and teaching in the current context of the study.

The research showed that both the students and the teachers had similar strong positive responses to the online methods. The perception and contribution from participants of the study to inform the implementation and design of such tasks is recommended. This leads to the following recommendations.

Firstly, teachers need to be trained and involved in designing such online tasks and materials to be used in active blended learning. More training in language teaching methodologies should be investigated to adapt the transition from a traditional to a CALL teacher. The administrators have to show their active role in encouraging teaching staff to participate in workshops on integrating technology into teaching by facility provision and, more importantly, understanding well about the contribution of teaching online, which help to make plans for developing of teaching training capability to give their teachers proper 
training. Proper training would help teachers achieve competencies of designing and implementing online simulated workplace tasks.

Secondly, time for the use of online tasks should be allocated satisfactorily. This can be achieved by building online learning sessions into class schedule or developing active blended courses. A guide session for teachers to have some techniques in designing tasks online should be included in such courses. Then, time in lab or simulation room should be adequately allocated to work for the use of CALL. In such simulation classes, students would be shown how to access the online tasks designed on the university LMS and the way to practice with different kinds of tasks. With adequate time allowed, teachers will require some assignments to help students learn with computers and encourage students to accomplish the assignments.

In the current study context, the online tasks design can be initiated at activity-level blending to support F2F activities. For example, online activities to support tasks for the topic "Make a request" or "Offer for help." This can be extended to course-level blending when more online activities are designed to be used with F2F activities such as online comparing and contrasting tasks to develop skills in connections with the cultural awareness.

\section{Conclusion}

It is evident that task design with the assistance of online LMS for blended learning can enhance business students' learning. Such blended learning environment, by combining online e-learning with text assignments, facilitated interactive activities with questioning techniques targeting communication skills, audio clips for simulated workplace situations and timely feedback as well as peer influence. This creates motivation for developing communicative competence required for learners. The benefits of the online tasks in the study are further emphasized in the current context of an increasing need of online teaching and learning worldwide due to the pandemic.

It is evident that online tasks, blended with classroom teaching and off-line tasks, effectively support business English learners to achieve communication skills including presentation skills, negotiation skills, making and responding to requests as well as working effectively in teams. The findings of the research provide support to and recommendation to develop and implement online tasks alongside with classroom learning and teaching to enable the objectives of business English programme at university for preparing learners to enter the workplace. The blended learning approach can be applied gradually at activity level, course level and programme level.

The recent pandemic highlighted the need for effective methodologies for active blended learning. It is now required that professionals in higher education to collect evidence base to inform future practice of such methodologies. Further significant research efforts should be directed towards collecting such evidence of the effectiveness and improvements of such methods. The support of higher education management professionals in securing funding for such research will be essential.

\section{References}

Banados, E. (2006), "A blended learning pedagogical model for teaching and learning EFL successfully through an online interactive multimedia environment", CALICO Journal, Vol. 23 No. 3, pp. 533-550.

Bargiela - Chiappinia, F. and Nickerson, C. (1999), "Business writing as social action", in Bargiela Chiappinia, F. and Nickerson, C. (Eds), Writing Business: Genres, Media and Discourses, Longman, London, pp. 1-32.

Bojović, M.D. (2017), "Blended learning as a foreign language learning environment”, TEME: Casopis za Društvene Nauke, Vol. 41 No. 4, pp. 1017-1036. 
JABES 29,3

Clarke, D.F. (1989), "Communicative theory and its influence on materials production", Language Teaching, Vol. 22, pp. 73-86.

Dat, B. (2008), "ELT materials used in Southeast Asia", in Tomlinson, B. (Ed.), English Language Learning Materials. A Critical Review, Continuum International, pp. 263-280.

Holliday, A. (2002), Doing and Writing Qualitative Research, Sage, London.

Kao, P.-L. and Windeatt, S. (2014), "Low-achieving language learners. In self-directed multimedia environments: transforming understanding", in Son, J.B. (Ed.), Computer-Assisted Language Learning: Learners, Teachers and Tools, Cambridge Scholars Publishing, Newcastle, pp. 1-20.

Koester, A. (2006), Investigating Workplace Discourse, Routledge, London.

Koester, A. (2010), Workplace Discourse, Routledge, London.

Levy, M. and Stockwell, G. (2006), CALL Dimensions: Options and Issues in Computer Assisted Language Learning, Lawrence Erlbaum Associates, London and New York, NY.

Magubhai, F., Marland, P., Daswood, A. and Son, J.B. (2004), "Teaching a foreign language: one teacher's practical theory", Teaching and Teaching Education, Vol. 20, pp. 291-311.

Marques, R.C. (2005), Language Teaching Methodologies in Computer-Assisted Language Learning: A Prospective Review, Simon Fraser University, British Columbia.

Neumeier, P. (2005), “A closer look at blended learning - parameters for designing a blended learning environment for language teaching and learning", ReCALL, Vol. 17 No. 2, pp. 163-178.

Nicole, A. and More, B. (2008), "Student perceptions of various E-learning components", Interdisciplinary Journal of E-Learning and Learning Objects, Vol. 4, pp. 113-135.

Nunan, D. (1991), Language Teaching Methodology, Prentice Hall, Hemel Hempstead, Herts.

Reay, J. (2001), "Blended learning: fusion for the future", Knowledge Management Review, Vol. 4 No. 3, pp. 1-6.

Richards, J. and Rodgers, T. (2011), Approaches and Methods in Language Teaching, Cambridge University Press, Cambridge.

Schnurr, S. (2013), Exploring Professional Communication, Routledge, London.

Sherman, J. (2003), Using Authentic Video in the Language Classroom, Cambridge University Press, Cambridge.

Silverman, D. (2005), Doing Qualitative Research, Sage, London.

Singh, H. and Reed, R. (2001), A White Paper: Achieving Success with Blended Learning, ASTD State of the Industry Report, American Society for Training and Development, Alexandria, Virginia, VA.

Skehan, P. (2003), “Task-based instruction”, Language Teaching, Vol. 36, pp. 1-14.

Stracke, E. (2007), "A road to understanding: a qualitative study into why learners drop out of a blended language learning (BLL) environment", ReCALL, Vol. 19 No. 1, pp. 57-78.

Tomlinson, B. (Ed.) (2003), Developing Materials for Language Teaching, Continuum, London.

Trabelsi, S. (2010), "Developing and trialling authentic Materials for business English students at a Tunisian university", in Tomlinson, B. and Masuhara, H. (Eds), Research for Materials Development in Language Learning, Continuum, pp. 103-120.

Van Lier, L. (1996), Interaction in the Language Curriculum: Awareness, Autonomy and Authenticity, Longman, Harlow.

Vietnam National University-HCMC (2008), The Record of Conference: The Improvement of English Language Training in Higher Education, Vietnam National University-HCMC, July 2008, Ho Chi Minh City.

Vinther, J. (2011), "Enhancing motivation with cultural narratives in computer-mediated communication”, Computer Assisted Language Learning, Vol. 24 No. 4, pp. 337-352. 
Vo, T.H.L. (2017), "Authentic materials to fulfil workplace requirements for vietnamese graduates", in Maley, A. and Tomlinson, B. (Eds), Authenticity in Materials Development for Language Learning, Cambridge Scholars, pp. 192-211.

Vo, T.H.L., Wyatt, M. and McCullagh, M. (2016), "Exploring the gap between Vietnamese workplace communication in English and English language teaching at a university", Asian ESP Journal, Vol. 12 No. 1, pp. 8-38.

Warschueer, M. and Healey, D. (1998), “Computers and language learning: an overview”, Language Teaching, Vol. 31, pp. 57-71.

Online

simulated tasks for English learning

Willis, J. (1996), A Framework for Task-Based Learning, Longman, London.

Wyatt, M. (2011), "Becoming a do-it-yourself designer of English language teaching materials", Forum: Qualitative Social Research, Vol. 12 No. 1, 33, pp. 1-38.

\section{Further reading}

Yates, J. and Orlikowski, W. (1992), "Genres of organizational communication: a structurational approach to studying communication and media”, Academy of Management Review, Vol. 17 No. 2, pp. 299-326.

\section{Corresponding author}

Thi Hong Le Vo can be contacted at: levth@ueh.edu.vn

For instructions on how to order reprints of this article, please visit our website:

www.emeraldgrouppublishing.com/licensing/reprints.htm

Or contact us for further details: permissions@emeraldinsight.com 